\title{
"Just google it": A internet como ferramenta metodológica complementadora do livro didático para o desenvolvimento do Foco na Forma em Wh-questions
}

\author{
Rangel Peruchi, \\ Universidade Federal Fluminense
}

\begin{abstract}
Resumo
O presente trabalho busca apontar algumas das características que fazem do livro didático de língua estrangeira um recurso metodológico ainda necessário na atual sociedade de informação. Utilizaremos o buscador google como uma ferramenta para o desenvolvimento no Foco na Forma em Wh-questions. A junção dessas duas ferramentas (livro didático e internet) pode funcionar como um enhanced tool tanto para a promoção da autonomia do aprendiz quanto no aperfeiçoamento no domínio da estrutura em foco.
\end{abstract}

Palavras-chave: livro didático de língua estrangeira, internet, Foco na Forma.

\begin{abstract}
This paper points out some of the features that make the textbook of a foreign language a methodological tool that is still necessary for the current society of information. We will use the internet research engine google as a tool for the development of Focus on Form in Wh-questions. The junction of both tools (textbook and internet) can work as an enhanced tool for the promotion of the student's autonomy and for the improvement in the command of the target language.
\end{abstract}

Keywords: foreign language textbook, internet, Focus on Form.

\section{INTRODUÇÃO}

Afirmar que a Internet oferece uma ampla gama de possibilidades para a aprendizagem da língua inglesa tornou-se clichê. O uso das infinitas capacidades de uso lá existentes requer, na verdade, maior atenção, criatividade e autonomia. Ao falarmos atenção temos em mente o fato das infinitas possibilidades de uso da informação disponível no meio virtual poderem gerar no aprendiz iniciante uma desorientação, já que ao não se ter atenção ao objetivo que se pretende com o uso da informação, não se saberá, muito provavelmente, aonde se quer chegar, ou seja, esse aprendiz será "guiado" a um labirinto sem início, meio ou fim. Ao mencionar criatividade no uso com a rede mundial 
de computadores, entendemos que o uso que se deve fazer dela não deva ser a mera reprodução das atividades existentes no livro didático, ou então uma complementação com baixa exigência de criatividade por parte do aprendiz. Ao falarmos autonomia, temos em mente que a rede oferece reais possibilidades de uso criativo, já que o aprendiz pode decidir que sites pretende explorar, assim como que uso fazer deles. Esse uso autônomo pode vir a funcionar de maneira relevante já que a motivação pelo tópico estará, certamente, presente.

Procuraremos nesse artigo levantar algumas questões com relação à utilidade e pertinência do livro didático nas aulas de língua inglesa. Buscaremos salientar alguns pontos que fazem do livro didático impresso um objeto necessário para o ensino, além de apontar alguns de seus pontos fracos. Ao apontarmos estes pontos, pretendemos chamar a atenção para a necessidade de não utilizá-los como única ferramenta metodológica, já que vivemos inseridos na sociedade de informação. Em seguida, apresentaremos algumas considerações com relação ao uso da rede mundial de computadores. Na atual sociedade, o uso que se faz da/na rede está amplamente difundido em nossas vidas e, por isso, acreditar que o aprendiz de língua inglesa também lá se encontra, nos leva a crer que a rede proporciona uma ferramenta útil e eficaz para o aperfeiçoamento no domínio de $W h$ questions na língua inglesa. A associação no uso do livro didático e da rede mundial de computadores pode ajudar o aprendiz, aprofundando seu conhecimento desse tópico gramatical, pois ao realizar buscas ele deverá atentar para a forma. Em seguida, apresentaremos alguns caminhos que podem ser seguidos ao se pensar no uso da rede como ferramenta complementadora do livro didático para a aprendizagem. Inserimos na parte Anexos algumas imagens do livro didático e de páginas de internet, para que nosso leitor possa seguir nosso raciocínio. Ao final, apresentaremos nossas conclusões e, se formos felizes nesse percurso, conseguiremos demonstrar ao nosso leitor de que tanto o livro didático de língua estrangeira quanto à rede mundial de computadores deveriam ser utilizadas como ferramentas de apoio mútuo.

\section{O LIVRO DIDÁTICO DE LÍNGUA ESTRANGEIRA E SUAS PRINCIPAIS CARACTERÍSTICAS}

O livro didático (doravante LD) de língua inglesa, por razões mercadológicas 
também, tende a ser visualmente atraente, já que sua aparência está em competição constante com os recursos visuais disponíveis no meio digital. Para Angell (2008), o LD é visualmente atrativo, tanto em seu aspecto visual quanto na facilidade que ele oferece ao professor no que se refere à preparação de aulas e na adequação do programa a uma carga horária definida.

Para que o conteúdo impresso circule nos mais variados contextos, ele precisa homogeneizar os conteúdos a serem trabalhados. Assim, o livro didático acaba se tornando um objeto homogêneo/homogeneizante para um universo heterogêneo de aprendizes. Em um primeiro momento, o acesso à informação selecionada e padronizada do livro didático fornece ao aprendiz o conhecimento gramatical para a compreensão de estruturas da língua-alvo e isso é bastante importante. Para Cunningsworth (1995) uma das primeiras funções do LD é o papel de apresentador de conteúdos, e é exatamente essa função um de seus principais méritos. Ora, mesmo que o LD não possa apresentar em quantidade e qualidade suficientes a informação necessária para um dado nível de proficiência, ele oportuniza a organização dos conteúdos e as expectativas linguísticas necessárias a alunos e professores, auxiliando no ensino (HYLAND, 2000). De acordo com Cullen $(222,2008)$, um conhecimento gramatical mais aprofundado capacita o aprendiz a compreender as sentenças da língua alvo de uma maneira mais precisa, atuando como uma força libertadora. É justamente o acesso a um conteúdo padronizado, organizado em níveis e com explicações gramaticais que faz do livro didático um objeto ainda necessário para o ensino de línguas.

Por exigências institucionais e sociais a sala de aula continua sendo o lugar no qual o LD e o professor são os agentes principais. Além disso, o conteúdo é sempre escolhido por outro alguém que não o aluno e, o que se aprende, muitas vezes, pode não ser útil ao aluno. Ou seja, muitas vezes as necessidades do aprendiz e o contexto sociocultural em que o aluno está inserido não são respeitados por ocasião da escolha de um livro didático (YAKHONTOVA, 2001). Nesse sentido, a sala de aula é um lugar onde se encenam os possíveis usos que serão assumidos pelos aprendizes, mas, em geral, os aprendizes não sabem o seu papel na "peça". Em outras palavras, o aprendiz tem acesso a estruturas gramaticais e exemplos de falas, mas ao receber o script pronto ele não sabe, muitas vezes, o peso de cada escolha linguística. Por outro lado, se o uso do LD em sala 
de aula não oferecesse vantagens (como já explanado) para o professor e para o aprendiz, seu uso muito provavelmente teria sido substituído pelas inúmeras possibilidades presentes no mundo virtual.

Em geral, o LD apresenta as estruturas gramaticais em uma sequência, na maioria das vezes em pares, como o Presente Simples e o Passado Simples, por exemplo (LONG \& CROOKES, 1993). Essa maneira de apresentar as estruturas de uma língua, sejam elas apresentadas concomitantemente ou em sequência, pode vir a beneficiar tanto aqueles alunos que estão tendo um contato inicial com uma estrutura dada ou aqueles que apresentam um domínio mais aprofundado (para o nível em que estão) já que comparações podem ser feitas. Para Nunan (2001), o livro didático de língua estrangeira baseia-se na premissa de que as regras de uma língua são aprendidas de maneira linear, e que os aprendizes deveriam demonstrar domínio completo de uma regra antes de passar para uma regra mais complexa. Concordamos com Nunan com relação a não linearidade do processo de aprendizagem de uma língua, mas não deixamos de pensar que no início do processo de aprendizagem de uma língua estrangeira certa gradação em termos de complexidade se faz necessária. O aprendiz precisa, inicialmente, ter acesso a um conteúdo básico da língua-alvo para que suas intuições iniciais ocorram. O LD (quando bem desenvolvido) oportuniza ao professor uma sequência de conteúdos coerentes para o trabalho em sala de aula, livrando-o do fardo de buscar conteúdos por conta própria a cada aula. Além disso, ao ter um conteúdo a ser seguido, o professor pode traçar mais claramente os objetivos a serem alcançados com seus alunos em termos de proficiência linguística. $\mathrm{O}$ momento de atuação em sala de aula exige por si próprio um número enorme de escolhas por parte do professor e, obrigar que o mesmo desenvolva o material didático para cada grupo específico seria contraproducente. Além disso, os diferentes níveis de proficiência linguística a serem alçados pelo aprendiz são mais facilmente delimitados se parâmetros institucionais são seguidos. Em outras palavras, o LD de língua estrangeira ao definir habilidades necessárias a serem alcançadas em cada nível, coopera para o estabelecimento de habilidades mínimas necessárias. Delegar ao professor de língua estrangeira a tarefa de avaliar o nível de proficiência dos aprendizes com base em suas próprias intuições, com relação às habilidades necessárias a cada nível, seria impreciso e ariscado. Impreciso porque após anos de contato com a língua-alvo, o 
professor pode vir a ter dificuldades em diferenciar os níveis de proficiência, pois domina a língua-alvo competentemente (temos em vista um professor proficiente na língua-alvo). Arriscado porque avaliar um aprendiz sem os parâmetros oferecidos por um livro didático (com base no Quadro Comum Europeu, 2009), deixaria o professor sujeito a todas as imprecisões inerentes ao ser humano, como a empatia, por exemplo.

\section{A INTERNET COMO FERRAMENTA COMPLEMENTADORA DO LIVRO DIDÁTICO DE LÍNGUA ESTRANGEIRA}

Diferentemente do LD que trabalha a previsibilidade e é sancionado por instituições, sendo delineado pela certeza da autoridade e controle (TADEU DA SILVA,1999), a internet é o local onde o aprendiz pode exercer sua autonomia com pleno controle, desde que saiba como fazê-lo.

Ao propormos o uso da internet como ferramenta metodológica, temos em mente a interatividade que pode ser alcançada por meio dela para o desenvolvimento na compreensão dos Wh-questions da língua inglesa. Leffa $(289,2011)$, nos afirma que a interatividade (presente na rede) é um artefato e que ao fornecer um feedback, esse artefato deixa de ser um instrumento de mediação para se tornar um agente de direito. Além disso, a evolução das ferramentas - dos primitivos machados de pedra até os computadores - reduziu a distinção entre pessoas e objetos. Nesse sentido, ao usar a rede para a aprendizagem de línguas cria-se uma intencionalidade e transforma-se o instrumento em agente.

Ao se pensar na promoção da autonomia do aprendiz e no aprofundamento do domínio de Wh-questions por meio da internet, uma das primeiras coisas que se deve ter em mente é o fato da leitura na tela do computador ser menos passiva do que aquela ocorrida no livro didático. Para Bolter (1991) e Landow (1992), a leitura na tela é um ato de criação de conhecimento por fontes variadas e ler no mundo digital requer algumas habilidades distintas daquelas requeridas na leitura do livro. Para Shetzer \& Warschauer (2000), a leitura online exige que o aprendiz encontre a informação por meio de ferramentas de busca, avalie rapidamente a credibilidade e adequabilidade da informação, decida rapidamente se irá ler a página ou salvá-la para leitura posterior, além de organizar e controlar a informação eletrônica que ele tenha salvado. Nenhuma das habilidades 
mencionadas acima são novas, já que a leitura no meio impresso também exige uma postura crítica, ativa e interpretativa.

A abordagem educacional padrão e vigente, que se utiliza do livro didático como fonte de informação, precisa, necessariamente, submetê-lo aos padrões vigentes da língua-alvo desse livro. Sendo assim, o livro didático não pode contemplar a maioria das necessidades/interesses dos seus leitores/aprendizes. A quantidade de informação presente na rede e a hipertextualidade dos textos exige ainda mais criticidade na leitura (WU, \& CANAAN, 2006). Nesse sentido, entendemos que o uso da internet como ferramenta complementadora favorece a negociação na multiplicidade de mídias e discursos existentes. Para o New London Group (1996), uma proposta metodológica que promova o multiletramento deve incluir elementos como: imersão em prática situada, overt instruction, critical frame e prática transformada.

$\mathrm{O}$ uso da internet como ferramenta para a aprendizagem é uma imersão em prática situada, em que pode haver uma situação comunicativa autêntica na qual os aprendizes podem colaborar com parceiros, negociar pontos complexos e criticamente avaliar a informação situada em contextos significativos. Além disso, a prática em contextos autênticos pode oportunizar o desenvolvimento de uma nova alfabetização tecnológica em contextos significativos. O overt instruction refere-se aos diferentes tipos de habilidades comunicacionais necessárias ao século XXI, que raramente se desenvolvem por meio de uma prática isolada. Ou seja, os aprendizes precisam ter a oportunidade de serem guiados pelo professor para que assim possam analisar criticamente o conteúdo, a coerência, a organização, o conteúdo pragmático, a sintaxe e o léxico da língua-alvo. Já o Critical framing relaciona-se a uma comunicação intercultural efetiva por meio do uso ocorrido na rede. O papel do professor não pode se resumir ao ensino de itens lexicais e, sim, a promoção da capacidade interpretativa do aprendiz. A atividade prática transformada permite ao aprendiz desenvolver suas habilidades comunicativas por meio de atividades mais complexas com base na prática, instrução e critical frame anteriormente apresentados, ou seja, levar o aprendiz a um conteúdo mais complexo, no qual ele possa aplicar seu conhecimento prévio e, no caso da internet, um ambiente mais real de comunicação. Esse quadro teórico vai muito além dos programas linguísticos tradicionais que se baseiam num conjunto de itens lexicais ou funcionais. 
Também vai além da noção de atividades baseadas em tarefa (quando essas tarefas se baseiam apenas no estudo de um item gramatical único) e sim, em projetos nos quais os aprendizes possam se utilizar de sua bagagem cultural, suas necessidades e interesses (STOLLER,1997). A atividade de aprendizagem baseada em projetos é mais indicada, todavia, para contextos educacionais que trabalham com aprendizes adultos em turmas pequenas e não com turmas com elevado número de aprendizes (HOLLIDAY,1994).

Tomando como base as ideias do New London Group (1996), a promoção do multiletramento no aprendiz de língua estrangeira pode ser alcançada à medida que o aprendiz venha a fazer descobertas linguísticas por conta própria, tomando como base um conhecimento prévio que pode vir a ser expandido, melhorado. O conhecimento adquirido por meio do livro didático e da instrução formal pode dar "asas" ao aprendiz, habilitando-o a fazer suas próprias escolhas com relação à leitura de conteúdo disponível na rede mundial de computadores. Em outras palavras, o conhecimento adquirido por meio da instrução formal pode levar o aprendiz a exercitar sua autonomia, já que ele adquire as ferramentas básicas e, assim, está mais apto a fazer suas escolhas. Se por um lado o LD trata a língua-alvo como uma sequência linear de estruturas a serem aprendidas, por outro lado, a leitura no meio virtual leva o aprendiz a ter acesso a língua em toda a sua complexidade. Nesse sentido, se em muitos momentos o LD sofre críticas pelo tratamento linear com que trata a língua-alvo, em outros, ele oferece ao aprendiz um terreno seguro para a internalização de estruturas gramaticais que serão colocadas em uso na leitura em meio virtual.

Ao propormos o uso da internet como ferramenta complementadora do livro didático na promoção da autonomia do aprendiz e no aprofundamento na compreensão dos Wh- questions, entendemos que a formação de um aprendiz autônomo exige um treinamento inicial. A metáfora da autonomia do aprendiz de língua estrangeira de Little (2000) sugere que sua autonomia é parte de uma espiral na qual o aprendiz progride a novos níveis de independência com base em movimentos de interdependência iniciais entre ele e outro aprendiz e/ou professor. Alinhamo-nos com Parreiras (2001) no entendimento de que a autonomia do indivíduo é uma das metas mais importantes da educação e que, ao alcançá-la, o aluno tem muito mais êxito em sua aprendizagem. Isso 
requer muito esforço e dedicação de sua parte, no entanto. Assim, a autonomia do aprendiz refere-se a onde, quando e $o$ que se pretende estudar. Por esse motivo, a internet, com todas as suas múltiplas possibilidades, é um instrumento didático valioso ao se encará-la como ferramenta complementadora do livro didático.

\section{FOCO NA FORMA}

Vários estudos têm demonstrado que o Foco na Forma pode facilitar o desenvolvimento da interlíngua do aprendiz. Há uma vasta gama de definições para essa técnica, por isso, trabalharemos aqui com a ideia de Foco na Forma (doravante FonF) apresentada por Jessica Willians (2001). Para a autora, o primeiro $F$ (foco) talvez seja o mais importante, pois se refere a questões relacionadas ao engajamento cognitivo e a processos de aprendizagem. Já o segundo $F$ (forma), não se refere apenas ao traço estrutural e, sim, a um traço lexical que pode ser alterado, melhorado, salientado, com o objetivo de chamar a atenção do aprendiz. Além disso, o processamento do sentido e da forma parecem ocorrer de maneira distinta, sendo a compreensão do sentido anterior a forma, como apontado por VanPatten (1996). Nesse sentido, uma possibilidade para aliviar o fardo no processamento de uma estrutura na língua alvo seria oportunizar ao aprendiz mais tempo para planejar sua produção (WILLIANS, 2001).

No trabalho com o LD, as oportunidades de averiguação na compreensão de $W h$ questions resumem-se a resolução de exercícios e a atividades orais nas quais, muitas vezes, o aprendiz apenas memoriza as perguntas a serem feitas. Se por um lado abandonou-se a mera repetição propagada por metodologias de cunho behaviorista, atualmente avalia-se o conhecimento da performance do aluno em atividades de roleplay, onde o que está em foco, na verdade, é a desenvoltura e memória do aprendiz. Nesse sentido, o trabalho com o FonF a ser realizado pelo aprendiz por meio da internet requer que o mesmo processe o sentido e a forma dos Wh-questions no momento em que for realizar suas buscas. A junção entre as atividades presentes no livro didático e na internet pode levar o aprendiz, em muitos casos, a perceber a diferença entre o seu domínio atual da estrutura (que pode ser deficiente) e a estrutura correta da língua-alvo. 
Assim, a atividade proposta aqui levaria o aprendiz a notice the gap ${ }^{l}$ ao realizar buscas online e a comparação entre sua percepção da estrutura em foco e daquela fornecida pelo buscador requer uma comparação cognitiva. Nesse sentido, o input recebido pelo aprendiz (em nosso caso fornecido pelo buscador google) precisa ser comparado a representações armazenadas na memória de longa duração ou a traços deixados na memória de tempo curto (WILLIANS, 2001).

\section{PROPOSTA METODOLÓGICA DE JUNÇÃO LIVRO DIDÁTICO-INTERNET}

Ao iniciar a aprendizagem da língua inglesa com o LD, o aprendiz certamente irá se deparar com o estudo do wh-questions. Com essa estrutura ele aprenderá a fazer perguntas como: Where are you from?; What do you do in your free time?; How old are you?; What time is it? etc. Apenas com esses exemplos podemos ter uma ideia da importância no entendimento de tal estrutura linguística e o quanto o aprendiz precisa verdadeiramente dominá-la. Em muitos momentos, o aprendiz compreende com certa precisão a estruturação do Wh-questions presente nos livros de língua inglesa (nível básico), mas demonstra dificuldade em aplicá-la em contextos mais naturais. Nesse sentido, a atividade com recursos disponíveis na rede mostra-se bastante interessante visto que o aprendiz por vir a aplicar um conhecimento gramatical importante, mas com poucas oportunidades de individualização, em contextos que exijam mais de seus recursos cognitivos. Assim, o estudo de Wh-questions por meio do LD pode vir a ser complementado com atividades de busca online nas quais o aprendiz tem a oportunidade de livremente escolher quais são as temáticas que lhe interessam. Nesse tipo de atividade, o aprendiz, mesmo munido de um conhecimento rudimentar da língua-alvo, pode iniciar a navegação por sites que versão sobre diferentes temáticas. A prática controlada, seriada e homogeneizada fornecida pelo LD encontra então o meio para ser individualizada pelo aprendiz. Apresentaremos abaixo uma sequência possível para a junção de conteúdo do LD com as ferramentas disponíveis na rede.

Inicialmente, como já apontado, o aprendiz teria contato com o Wh-questions e com os exercícios disponíveis no livro American English File 1. Apresentamos no anexo I a

\footnotetext{
${ }^{1}$ Notice the gap ocorre quando aprendizes notam que a sua interlíngua difere da língua-alvo. Ou seja, eles percebem que estão cometendo um erro, uma forma estabilizada da sua interlíngua. Isso envolve tanto a percepção da interlíngua e da forma correta na língua-alvo havendo uma junção do input e do output (SWAIN, 1998).
} 
proposta do livro acima mencionado para o estudo desse item gramatical e, no anexo II, um exercício de fixação na versão online do livro. Já no anexo III o exercício é inserido em uma atividade online como uma tarefa de entretenimento, inserido em um jogo de vídeogame (Anexo III). Apesar de visualmente atraente e da exigência direta da participação do aprendiz para o andamento da tarefa, percebemos que o exercício é em si simples, pois exige, na verdade, apenas a estruturação lógica da sentença. Ou seja, é um exercício simples e com baixo nível de exigência por parte do aprendiz. O meio virtual, nesse caso, apenas oferece um suporte mais interativo que o livro didático, mas a exigência na resolução é um tanto simples. Nesse sentido, percebe-se que muitas vezes a junção do livro didático com a internet não oferece em si oportunidades instigantes e promotoras de autonomia e, sim, a mera transposição de atividades do livro didático com os recursos tecnológicos da rede mundial de computadores. Como visualizamos a internet como uma ferramenta complementadora do livro didático, tomados o conteúdo presente no anexo I como o ponto inicial para a promoção na leitura em meio virtual com vistas à fixação e entendimento de Wh-questions. Assim, a continuação do estudo de Whquestions poderia ser a seguinte: o professor poderia propor uma atividade na qual os aprendizes acessassem a pergunta; What are the most asked questions to google? (Anexo III). O aprendiz teria então a oportunidade de praticar a estrutura previamente estudada para então aplicá-la em um contexto mais significativo e individualizado. Ao acessar a tela com um quadro das perguntas mais realizadas ao google ele visualizaria outras perguntas realizadas com a estrutura do Wh-questions e, assim, teria acesso a uma prática melhorada. Um ponto importante a ser salientado é que ao digitar perguntas (no site já mencionado) perguntas similares e/ou a própria pergunta do aprendiz aparecem automaticamente, gerando no aprendiz a possibilidade de contrastar seu modo de escrever a outros possíveis. Muitas vezes, ao se digitar uma pergunta tem-se a possibilidade de visualizar a(s) maneira (s) amplamente utilizadas para a realização de uma pergunta. Após acessar a página inicialmente sugerida pelo professor, o aprendiz poderia, após visualizar as perguntas mais realizadas ao buscador google, selecionar aquelas que mais lhe interessassem. Nesse momento, ele estaria exercendo sua autonomia ao eleger os caminhos que pretende seguir para a leitura de textos. Além disso, - faria uso do conhecimento gramatical adquirido por meio do livro didático. Esse conhecimento 
gramatical pode levar o aprendiz tanto a leitura das perguntas apresentadas pelo buscador assim como a uma possível leitura dos textos relacionados às perguntas visualizadas e/ou buscadas por ele. Em resumo, o conhecimento gramatical adquirido em contexto formal e de maneira guiada pode funcionar como uma ferramenta inicial na busca de textos online. Nesse sentido, a junção do livro didático e a internet complementam-se, pois se na primeira há um recorte, uma gradação no conteúdo da língua-alvo que parecem ser tão importantes nos estágios iniciais de aprendizagem da língua-alvo, na segunda, há a possibilidade de uso de um conhecimento prévio para a expansão e prática da leitura.

\section{CONSIDERAÇÕES FINAIS}

O uso da internet como ferramenta complementadora do livro didático deve ocorrer de maneira a promover o uso de maneira autônoma e criativa. Se na sala de aula há a possibilidade do professor fornecer um conteúdo básico de conhecimento léxicogramatical em um dado nível, na internet, o aprendiz pode expandir esse conhecimento com a bagagem linguística previamente adquirida para então desenvolver certas tarefas necessárias na busca de conteúdo online. A sequência organizada de conteúdo fornecido pelo livro didático ajuda o aprendiz a adquirir as ferramentas linguísticas necessárias para que um desenvolvimento mais autônomo possa ocorrer na internet.

O aprofundamento no conhecimento no Foco na Forma pode ser melhorado por meio do uso da internet, já que ao propor que o aprendiz realize buscas online de maneira mais autônoma, cria-se o meio para que o mesmo se utilize de seu conhecimento na formação de Wh-questions. Ao realizar uma busca online com a utilização dessa estrutura gramatical, o aprendiz precisa fazer uso de sua memória de longo e curto prazo, além de ter acesso a um feedback digital. Ao realizar as buscas o domínio atual do aprendiz com relação ao Wh-question e os novos conhecimentos que podem surgir como resultado de suas buscas oferecem reais oportunidades de averiguação de hipóteses linguísticas por parte do aprendiz. Ou seja, o livro didático oferece o conteúdo mais formalizado e a metalinguagem da estrutura gramatical enquanto a realização de atividades de busca online oferece a aplicação no domínio dessa estrutura linguística para a construção de sentenças. Assim, o contraste entre as sentenças digitadas pelo aprendiz e aquelas sugeridas pelo próprio buscador podem promover uma interação entre o aprendiz e o 
meio digital. O resultado dessa interação livro didático-internet oferece não apenas um uso criativo da internet, mas a oportunidade efetiva para a consolidação da forma de $W h$ questions.

\section{REFERÊNCIAS}

BOLTER, J. D. (1991). Writing space: The computer, hypertext, and the history of writing. Hillsdale, NJ: Lawrence Erlbaum Associates.

CULLEN, R. (2008). Teaching grammar as a liberating force. ELT Journal. 62:221230 .

CUNNINGSWORTH, A. (1995) Choosing your coursebook. Oxford: Heineman.

ELLIS, R. (1993). The structural syllabus and second language acquisition. TESOL Quarterly 27:91-113. doi: 10.2307/3586953

ELLIS, R.(2003). Task-based language learning and teaching. Oxford, UK: Oxford University Press.

ELLIS, R. (2006). Current issues in the teaching of grammar: An SLA perspective. TESOL Quarterly, 40:83-107.

HYLAND, K. Disciplinary discourses: social interactions in academic writing. London: Pearson Education, 2000. p. 105-131.

LANDOW, G. P. (1992). Hypertext: The convergence of contemporary critical theory and technology. Baltimore: John Hopkins University Press.

LONG, M \& G CROOKES. (1993). Units of analysis in syllabus design: The case for task. In Crookes, G \& S. Gass (Eds.), Tasks in a pedagogical context. Clevedon, UK: Multilingual Matters. 9-54

LITTLE,D.(2000). Learner autonomy and human interdependence: Some theoretical and practical consequences of a social-interactive view of cognition, learning and language. In: SINCLAIR, B.; MCGRATH,L; LAMB,T. (Eds.). Learner autonomy, teacher autonomy: Future directions, London: Longman, 200.p.15-23.

OXEDEN,C \& LATHAM-KOENIG,C \&SELIGSON, P.(2008) American English File 1. Oxford do Brasil 
PARREIRAS, V.A.(2001). Estratégias de aprendizagem on-line e autonomia: uma relação biunívoca ou antagônica. In: Paiva, V.L.M.O. (org.). Interação e aprendizagem em ambiente virtual. Belo Horizonte: Faculdade de Letras, UFMG, PP.192-206.

SILVA, Tomaz T. da. (1999). O currículo como fetiche; a poética e a política do texto curricular. Belo Horizonte: Autêntica.

SWAIN, M. (1995) Three functions of output in second language learning. In G. Cook \& B. Seidlhofer (eds.), Principle and practice in applied linguistics. Oxford: Oxford University Press, 125-144.

WU, Li \& CANAAN, Ben (2006). The Impact of Globalization and the Internet on English Language Teaching and Learning. DanHeilongjiang University, School of Western Studies.

WILliANS, J. (2001). Focus on Form: Research and its application. Revista Brasileira de Linguística Aplicada, v.1, n.1,31-52.

WILLIANS, J.(1999). Learner-generated attention to form. Language Learning Research, v.49, p.583-625.

YAKHONTOVA, T. (2001). Textbooks, contexts and learners. English for Specific Purposes, Ann Arbor, vol. 20, p. 397-415.

OXFORD University Press. Disponível em:

http://elt.oup.com/student/americanenglishfile/1/a_grammar/file07/grammar07_b0 1 ?cc=br\&selLanguage=pt. Acessado em 11/04/2013

Serch Insights. Disponível em:

http://searchinsights.wordpress.com/2011/09/01/the-most-asked-questions/.

Acessado em 03/04/2013

Serch Insights. Disponível em:

http://searchinsights.files.wordpress.com/2011/09/questions.jpg. Acessado em 03/04/2013

\section{O AUTOR}

Rangel Peruchi, doutorando, UFF

E-mail: rangel_peruchi@yahoo.com.br 


\section{ANEXO I}

$12 / 04 / 13$

American English File | Oxford University Press

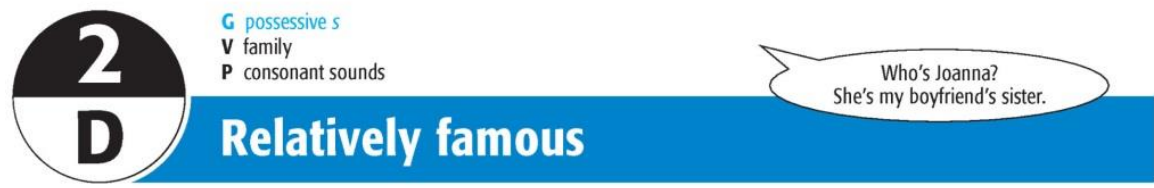

1 GRAMMAR possessive $s$

a Look at the photo. What does 's mean?
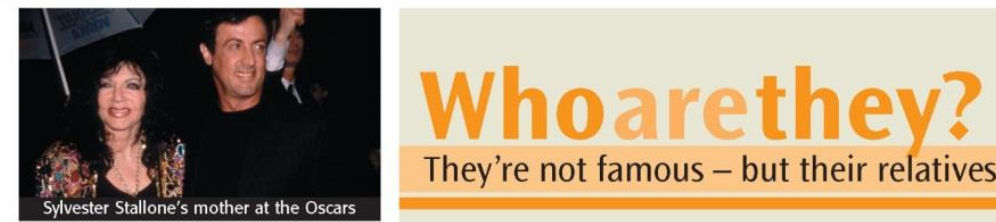

They're not famous - but their relatives are!
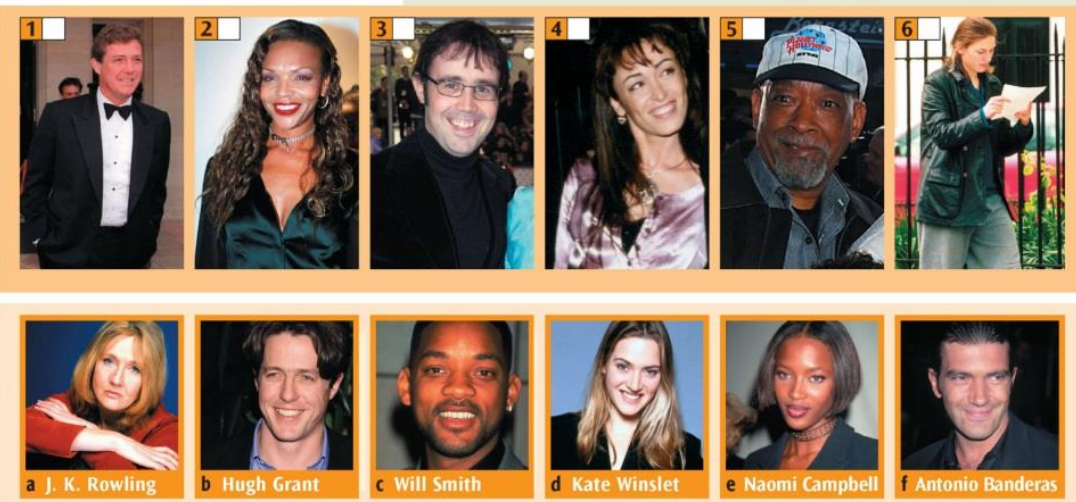

b Match the people in photos 1-6 with their famous relatives a-f. In pairs, ask and answer questions. Use these words. mother father brother sister (ex-) wife (ex-) husband Who's he? (picture 1) (I think) he's (I think) he's
Hugh Grant's brother.

c 2.13 Listen and check.

d Listen and repeat the sentences.

e p.124 Grammar Bank 2D. Read the rules and do the exercises. $\mathrm{f}$ Whose is it? Match the people a-f with their possessions. (I think) it's J. K. Rowling's pen.
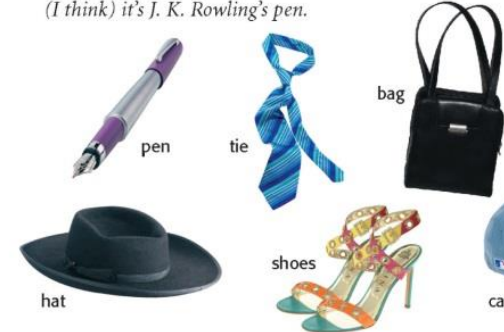
ANEXO II

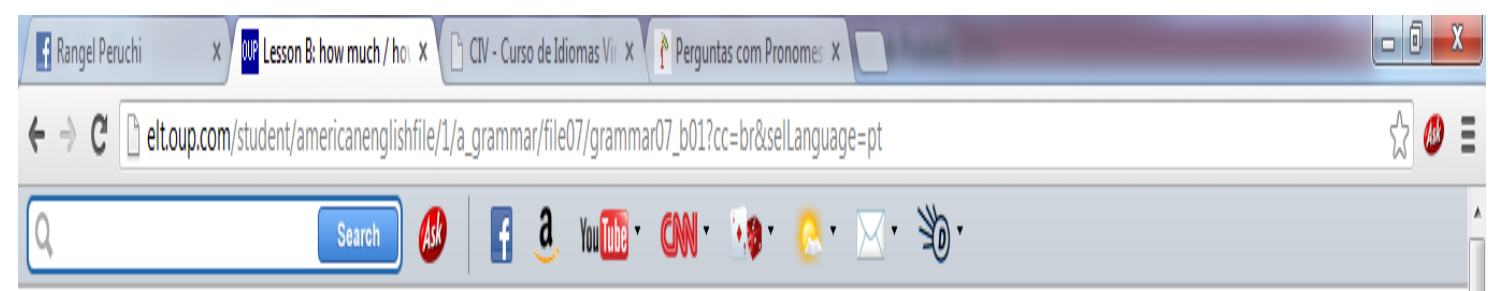

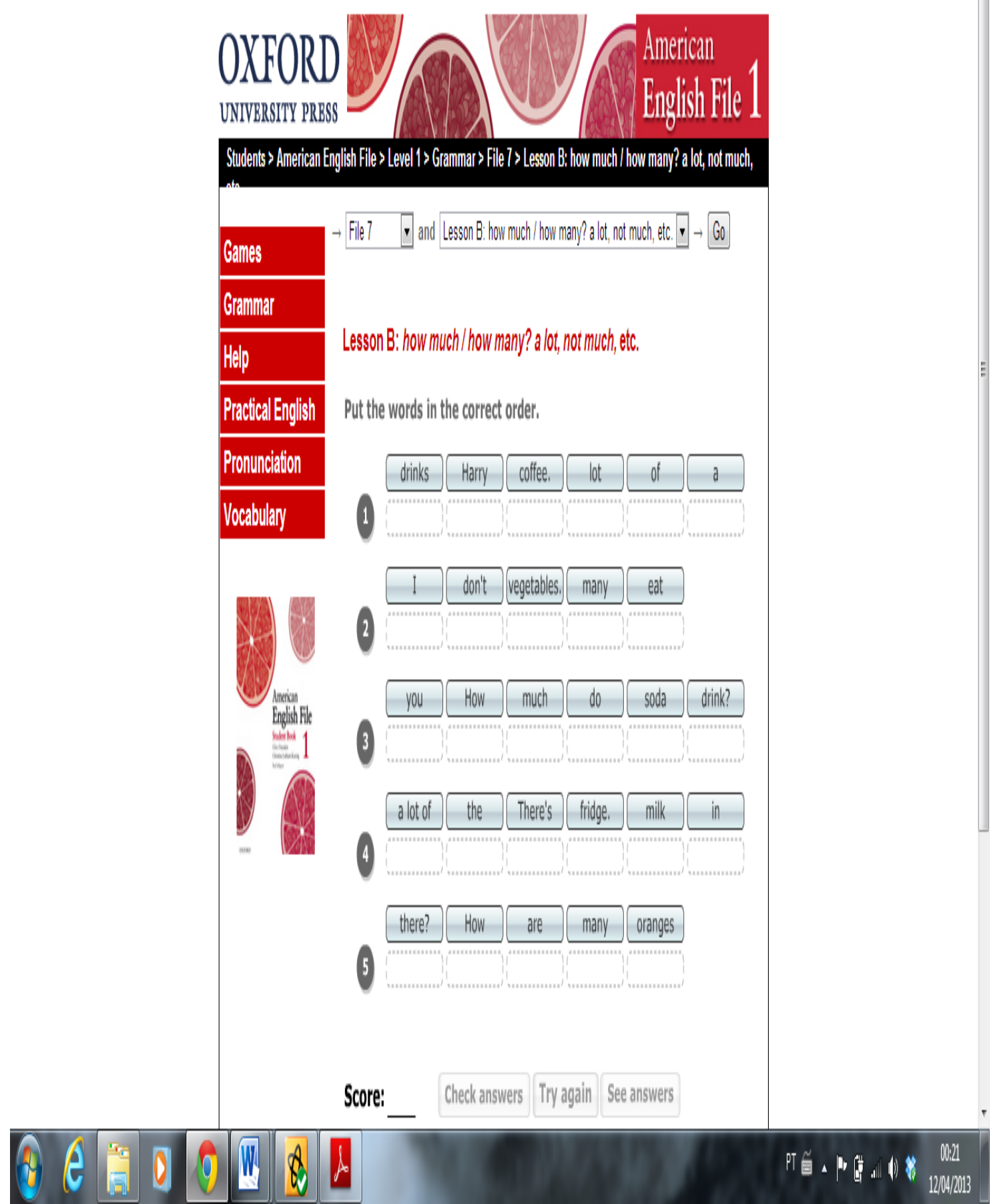


ANEXO III

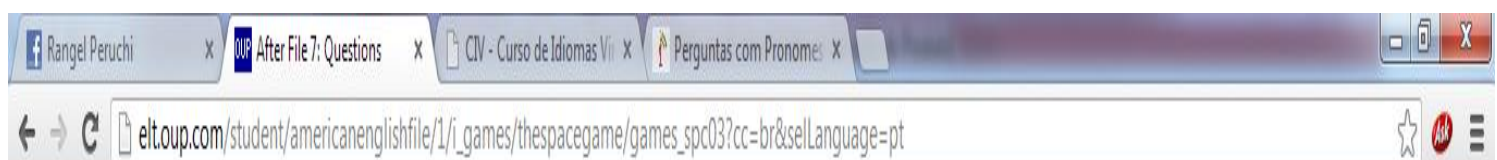

Q

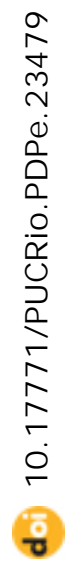

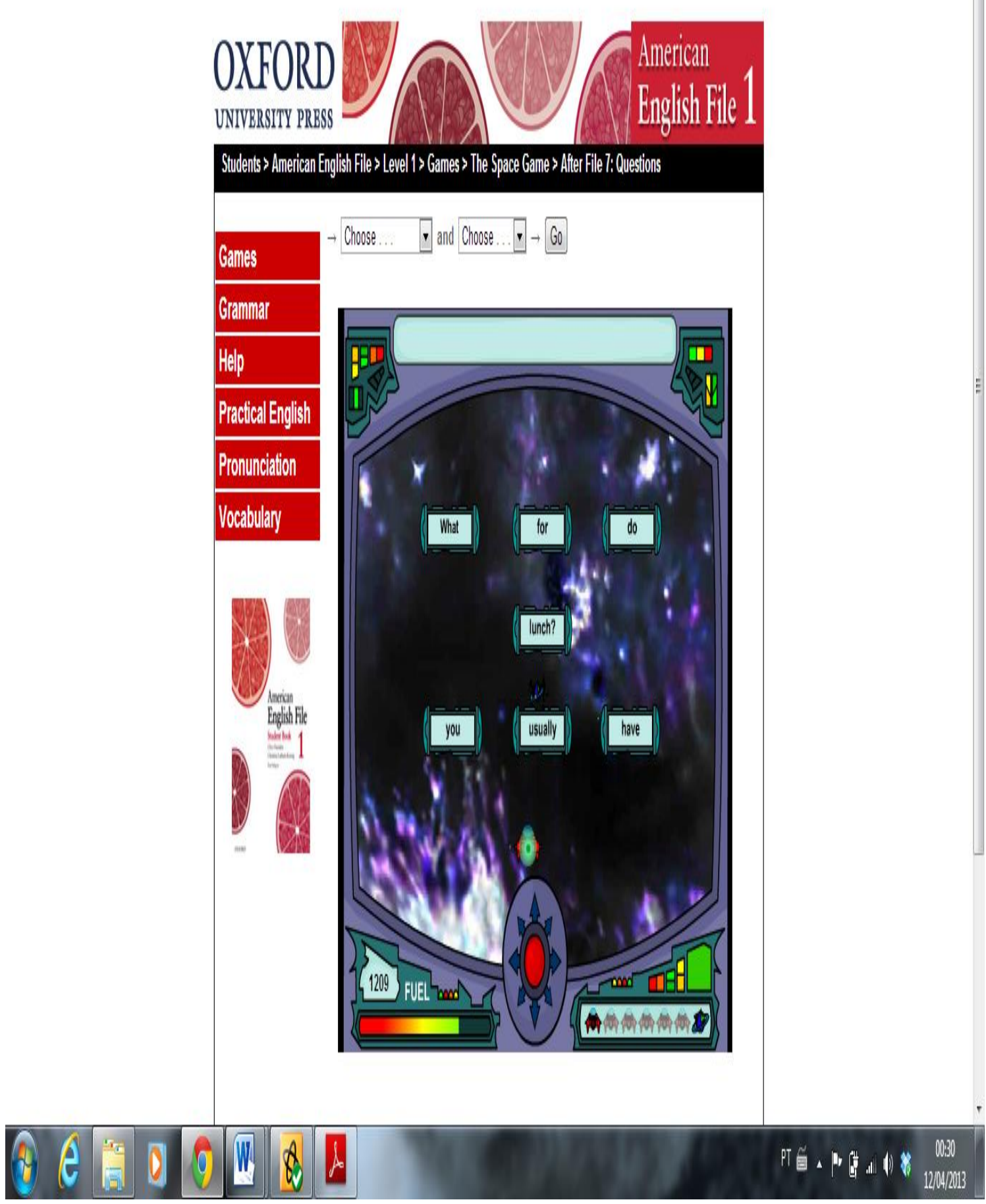




\section{ANEXO IV}

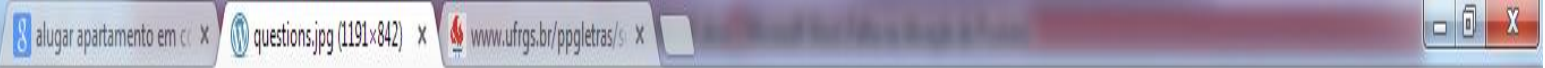

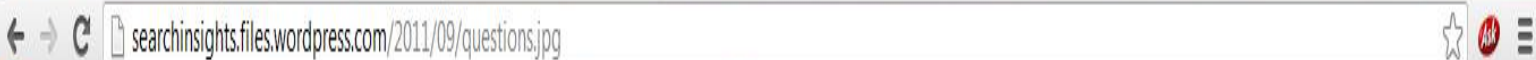

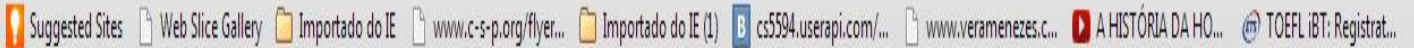

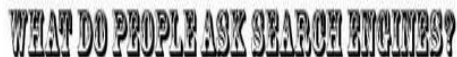

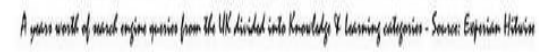

Nature

Most likely to adk Percentopo o searches

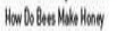

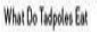

How Do Caspurt

Why Docus hew Wiston

Whithafosad

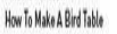

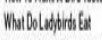

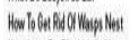

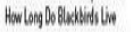

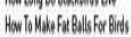

Howan foust found

What Dopolos bers but

Howillabathabi ing

Whicloborllas fat

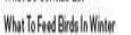

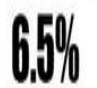

Science

Heallh

Most likely to ask Percentage of searches

How folose Wingth

Whet is from Silloulor

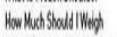
that arequedilins

Whan Dow Hering Skeknew a

Sart

How 10 Sexp Soring

What Cwesc Crump

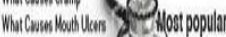

How To Ge Propanat

Why OW Wh Orum

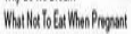

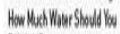

Dinkaby

Whatily $\mathrm{Bm}$

How To Sep Pramiun Evava.

Most popular

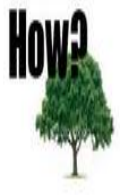

Most likely lo ask
Whis thesholue

Peccentape ol saraches

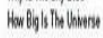

What Hopers What Ku D D

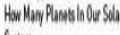

Sylum

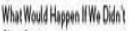

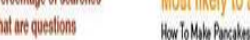

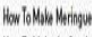

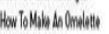

Hew Tocoushing

How Tocal Covpritten

How to Coul Bentoot

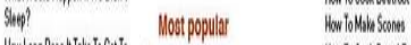

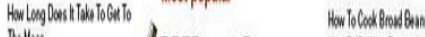

Donllow

When Wil The How

How Biglision Sun

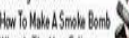

When sthe Nereteclow

What heychos

What 60 in

Gardening

Nost likely to ask Pecerilaye of searctien

Hew To Grow Pouton

than ire quesion:

Religion

$\begin{array}{ll}\text { Most likely to ask Percentage o o varches } \\ \text { Whons bi } & \text { that reve quedions }\end{array}$

How ToBailat Eg

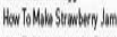

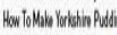

How ToNow Opadis

Howlowlobiantegy

How TOMala lemonoses

Hew Tolation Fidy

History

Most likely to ask Percentageo o searches

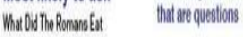

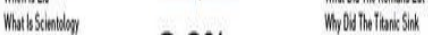

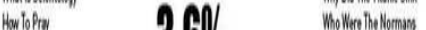

Weat brimdin

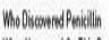

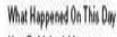

$10 / 2$

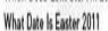

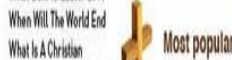

How To Mola AMunon

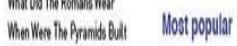

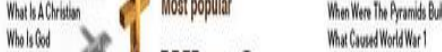

Whanlibiwal

Whit

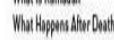

Whens bood firaty 2011

What bthenenthe

Whatslam

Learning

Hew ToGouguricic

Hom To Prum Rouses

Then Toplut Potions

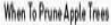

8.3\%

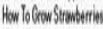

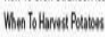

How To Goucreross

Most likely to ask

How Jolleded cow betere

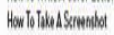

Hento Spend b horome

Howlosing

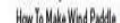

How lowerealenter

Hew ov wa Tiver

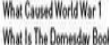

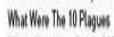

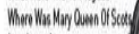

Improment

How Todtuck A Caste

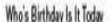

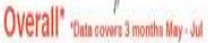

Hew Tolv boding

Most populat

How To Dibib Frocion

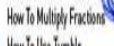

Percentage of searches

How

What

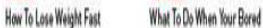

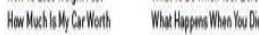

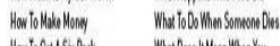

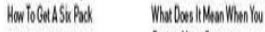

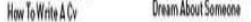

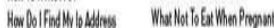

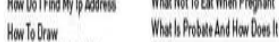

Hew ToGer Ro

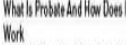

How Old bi tha duen

Ilamn

Howidvinitater 